\title{
COMPARISON BETWEEN THE TONOGRAPHIC EFFECTS OF PILOCARPINE AND ECHOTHIOPHATE IODIDE IN GLAUCOMA SIMPLEX*
}

\author{
BY \\ R. FISHER, REDMOND SMITH, AND CAROL WHEELER \\ London
}

ACCORDING to Becker, Pyle, and Drews (1959) the instillation of miotics into glaucomatous eyes may be followed by an increase in the tonographically calculated coefficient of aqueous outflow, together with lowering of intra-ocular pressure. Although there is a well-accepted clinical grading of the various miotics by "strength" from pilocarpine at the lower end to the powerful cholinesterase inhibitors at the upper, our knowledge is still surprisingly scanty regarding exact dose-response relationships. The study here described was set up to discover whether pilocarpine 2 per cent. used three times a day or echothiophate iodide $0 \cdot 12$ per cent. used once at night, gave different tonographic and tonometric values on the same eyes.

\section{Materials and Method}

The clinical material consisted of 11 patients (18 eyes) suffering from open-angle (chronic simple) glaucoma. All had been under observation for a minimum period of three months and had been subjected to the usual investigations: general ophthalmological examination, gonioscopy, applanation tonometry, and visual field studies. Only wide-angle cases were admitted and none of the eyes studied had been subjected to any form of ocular surgery.

The apparatus used in the study was the Haag Streit 900 slit-lamp with applanation tonometer and the Schwarzer electronic tonometer with recorder. Each patient was treated with pilocarpine 2 per cent. drops three times daily, and was instructed to instil one drop in each eye at 8.00 a.m., 4.00 p.m., and 10.00 p.m., and after a minimum period of one week on this therapy applanation tonometry and tonography were carried out. The time of day at which this examination was made varied from patient to patient.

Pilocarpine therapy was then changed to echothiophate (Phospholine) iodide $0 \cdot 12 \mathrm{per}$ cent., one drop in each eye every night at 10.00 p.m. One week later applanation tonometry and tonography were again carried out in each case at the same time of day as upon the first occasion.

Tonography results were recorded in the rigidity-corrected form by the graphic method of Moses and Becker (1958). 
Results

In Table I are recorded details of the eyes studied.

In Table II are recorded the results of a direct comparison between the pressure, outflow facility, and scleral rigidity of eyes initially treated by pilocarpine, and finally treated by Phospholine Iodide. The pressure shows a significant fall of over $3 \mathrm{~mm}$. $\mathrm{Hg}(\mathrm{P}<0.02)$ and an even more significant increase $(0.082)$ in outflow facility $(\mathrm{P}<0.01)$. The scleral rigidity in Phospholine Iodide-treated eyes also

TABLE I

Effects of Pilocarpine and Phospholine Iodide in 18 Eyes

\begin{tabular}{|c|c|c|c|c|c|c|c|c|}
\hline \multicolumn{6}{|c|}{ Pilocarpine } & \multicolumn{3}{|c|}{ Phospholine Iodide } \\
\hline Case No. & Sex & $\begin{array}{c}\text { Age } \\
\text { (yrs) }\end{array}$ & Pressure & Uncorrected C & Corrected C & Pressure & Uncorrected C & Corrected C \\
\hline \multicolumn{3}{|c|}{ Pilocarpine-controlled } & & & & & & \\
\hline 13 & $F$ & 62 & 15 & $0 \cdot 24$ & $0 \cdot 24$ & 12 & 0.22 & $0 \cdot 25$ \\
\hline 8 & $F$ & 69 & 18 & $0 \cdot 22$ & $0 \cdot 22$ & 21 & 0.25 & $0 \cdot 23$ \\
\hline 14 & $\mathbf{M}$ & 29 & 21 & $0 \cdot 15$ & $0 \cdot 11$ & 20 & $0 \cdot 14$ & $0 \cdot 17$ \\
\hline 21 & $\mathrm{~F}$ & 66 & 18 & $0 \cdot 15$ & $0 \cdot 15$ & 21 & $0 \cdot 19$ & $0 \cdot 23$ \\
\hline 8 & $\mathbf{F}$ & 69 & 20 & $0 \cdot 15$ & $0 \cdot 17$ & 19 & $0 \cdot 31$ & $0 \cdot 29$ \\
\hline 19 & $\mathbf{M}$ & 70 & 21 & $0 \cdot 16$ & $0 \cdot 17$ & 19 & $0 \cdot 33$ & $0 \cdot 35$ \\
\hline 21 & $\mathbf{F}$ & 66 & 21 & $0 \cdot 16$ & $0 \cdot 15$ & 21 & $0 \cdot 15$ & $0 \cdot 13$ \\
\hline \multicolumn{3}{|c|}{ Pilocarpine-uncontrolled } & & & & & & \\
\hline 3 & $\mathbf{M}$ & 75 & 27 & $0 \cdot 13$ & $0 \cdot 13$ & 20 & $0 \cdot 22$ & $0 \cdot 22$ \\
\hline 5 & $\mathbf{F}$ & 65 & 27 & $0 \cdot 18$ & 0.23 & 29 & $0 \cdot 30$ & 0.45 \\
\hline 14 & $\mathbf{M}$ & 29 & 24 & $0 \cdot 13$ & $0 \cdot 12$ & 21 & $0 \cdot 16$ & $0 \cdot 16$ \\
\hline 29 & $\mathbf{F}$ & 74 & 24 & $0 \cdot 15$ & $0 \cdot 16$ & 15 & $0 \cdot 17$ & $0 \cdot 17$ \\
\hline 20 & $\mathbf{M}$ & 68 & 22 & $0 \cdot 15$ & $0 \cdot 21$ & 17 & $0 \cdot 23$ & 0.39 \\
\hline 3 & $\mathbf{M}$ & 75 & 24 & 0.05 & 0.09 & 21 & $0 \cdot 12$ & $0 \cdot 20$ \\
\hline 15 & $\mathbf{M}$ & 68 & 30 & $0 \cdot 20$ & $0 \cdot 46$ & 22 & $0 \cdot 15$ & $0 \cdot 14$ \\
\hline 19 & M & 70 & 23 & $0 \cdot 12$ & 0.06 & 20 & 0.24 & 0.26 \\
\hline 26 & $\mathbf{M}$ & 59 & 22 & 0.08 & $0 \cdot 13$ & 18 & 0.08 & $0 \cdot 18$ \\
\hline 29 & $\mathbf{F}$ & 74 & 22 & 0.17 & $0 \cdot 17$ & 13 & $0 \cdot 24$ & $0 \cdot 22$ \\
\hline 20 & $\mathbf{M}$ & 68 & 25 & $0 \cdot 19$ & $0 \cdot 22$ & 20 & $0 \cdot 19$ & 0.32 \\
\hline
\end{tabular}

TABLE II

COMPARISON BETWEEN 18 EYES INITIALLY ON

Pilocarpine and subsequently on PhosPholine Iodide

\begin{tabular}{|c|c|c|c|c|c|c|c|c|}
\hline \multirow[b]{2}{*}{ Quantity } & \multicolumn{3}{|c|}{ Pilocarpine } & \multicolumn{3}{|c|}{ Phospholine Iodide } & \multirow{2}{*}{$\begin{array}{l}\text { Prob- } \\
\text { ability } \\
\text { (P) }\end{array}$} & \multirow[b]{2}{*}{ Remarks } \\
\hline & $\begin{array}{l}\text { Mean } \\
\text { Value }\end{array}$ & $\begin{array}{c}\text { Standard } \\
\text { Deviation } \\
\sigma\end{array}$ & $\begin{array}{c}\text { Standard } \\
\text { Error } \\
\text { of Mean } \\
(\sigma \mathrm{m})\end{array}$ & $\begin{array}{l}\text { Mean } \\
\text { Value }\end{array}$ & $\begin{array}{c}\text { Standard } \\
\text { Deviation } \\
\sigma\end{array}$ & $\begin{array}{c}\text { Standard } \\
\text { Error } \\
\text { of Mean } \\
(\sigma \mathrm{m})\end{array}$ & & \\
\hline Pressure & $22 \cdot 6$ & $4 \cdot 3$ & $1 \cdot 0$ & $19 \cdot 2$ & $3 \cdot 9$ & 0.9 & $<0.02$ & Significant \\
\hline $\begin{array}{l}\text { Outflow } \\
\text { facility } \\
\text { (corrected) }\end{array}$ & $0 \cdot 160$ & 0.06 & 0.015 & $0 \cdot 242$ & $0 \cdot 08$ & 0.02 & $<0.01$ & $\begin{array}{l}\text { Highly } \\
\text { significant }\end{array}$ \\
\hline $\mathrm{Po} / \mathrm{C}$ & 141 & 79 & 18 & 79 & 39 & 9 & $<0.01$ & $\begin{array}{l}\text { Highly } \\
\text { significant }\end{array}$ \\
\hline $\begin{array}{l}\text { Scleral } \\
\text { rigidity } \\
\text { (E) }\end{array}$ & 0.0205 & 0.006 & 0.0004 & 0.0185 & 0.004 & 0.001 & $0 \cdot 2$ & $\begin{array}{l}\text { Not } \\
\text { significant }\end{array}$ \\
\hline
\end{tabular}


shows a fall of 0.002 . It is of interest in this series that the decrease in ocular rigidity is not significant, although a fall in ocular rigidity as a result of the use of stronger miotics has been recorded by other observers.

In order to investigate more fully the final response to Phospholine Iodide, the cases were further sub-divided into four groups: Group 1, eyes responsive to initial pilocarpine treatment-as judged by an ocular tension of or below $21 \mathrm{~mm} . \mathrm{Hg}$ (7 cases); Group 2, the same eyes on Phospholine Iodide; Group 3, the eyes which were not controlled by pilocarpine, with tensions above $21 \mathrm{~mm}$. Hg; and Group 4, these eyes on Phospholine Iodide. The mean ocular tensions and outflow facilities of these groups are shown in Table III.

TABLE III

Comparison between CASES initially on Pilocarpine

WITH I.O.P. 21 MM. Hg AND BeLOW (Group 1) AND ABOVE 21 MM. Hg (Group 3)

\begin{tabular}{|c|c|c|c|c|c|}
\hline $\begin{array}{c}\text { Group } \\
\text { No. }\end{array}$ & Drug & $\begin{array}{c}\text { Mean } \\
\text { Pressure } \\
(\mathrm{mm} . \mathrm{Hg})\end{array}$ & $\begin{array}{l}\text { Outflow } \\
\text { Facility } \\
\text { (corrected) }\end{array}$ & $\begin{array}{c}\text { Standard } \\
\text { Deviation } \\
(\sigma)\end{array}$ & Remarks \\
\hline 1 & Pilocarpine & $19 \cdot 1$ & $0 \cdot 173$ & 0.04 & \multirow{2}{*}{$\begin{array}{l}\text { Controlled } \\
\text { by pilocarpine } \\
\text { initially }\end{array}$} \\
\hline 2 & Phospholine Iodide & $19 \cdot 0$ & $0 \cdot 236$ & 0.07 & \\
\hline 3 & Pilocarpine & $24 \cdot 5$ & $0 \cdot 153$ & 0.05 & \multirow{2}{*}{$\begin{array}{l}\text { Uncontrolled } \\
\text { by pilocarpine } \\
\text { initially }\end{array}$} \\
\hline 4 & Phospholine Iodide & $19 \cdot 6$ & $0 \cdot 247$ & 0.09 & \\
\hline
\end{tabular}

Discussion

Since the mean pressures and outflow facilities of eyes controlled on pilocarpine and subsequently placed on Phospholine Iodide (Groups 1 and 2) were so similar, it was decided to test the variation in outflow facility for the whole series of cases for homogeneity. It was found that the cases so grouped depart very significantly from homogeneity $(Z=0.8164)$ with a probability $P$ of less than 0.001 .

The next step was to compare each group for significant differences with the other three groups. In such a series of four groups six comparisons (A, B, C, D, E, F) were possible and these are shown in Table IV.

Direct comparison between pilocarpine and Phospholine Iodide shows considerable divergence in controlled cases (comparison A) and uncontrolled cases (comparison F). In pilocarpine-controlled cases subsequent Phospholine Iodide treatment did not significantly increase the outflow facility. If it be accepted that the main action of miotics is to increase traction on the scleral spur and so open up the trabecular meshwork, then pilocarpine and Phospholine Iodide of the strengths used in this trial have a similar effect if the eye is controlled initially by pilocarpine. In eyes in which the tension was uncontrolled on pilocarpine, however, Phospholine Iodide increased the outflow facility (increase of 0.094$)$ very significantly $(P<0.02)$. It would seem that in these cases Phospholine Iodide has a further and distinct action which is separate from pilocarpine.

We may now consider all the cases initially treated by pilocarpine (comparison B). In this instance there was no significant difference in outflow facilities between 
TABLE IV

Significance of Outflow Facility Between Groups 1 to 4

\begin{tabular}{c|c|c|c|c|c}
\hline Comparison & Groups & $\begin{array}{c}\text { Differences } \\
\text { of Means }\end{array}$ & $\begin{array}{c}\text { Standard } \\
\text { Error of } \\
\text { Difference }\end{array}$ & $\begin{array}{c}\text { Probability } \\
\text { (P) }\end{array}$ & Remarks \\
\hline A & $\begin{array}{c}1.2 \\
\text { (Pilocarpine-Phospholine) }\end{array}$ & 0.063 & 0.039 & 0.15 & Not significant \\
\hline B & $\begin{array}{c}1.3 \\
\text { (Pilocarpine-Pilocarpine) }\end{array}$ & 0.020 & 0.035 & 0.60 & Not significant \\
\hline C & $\begin{array}{c}1.4 \\
\text { (Pilocarpine-Phospholine) }\end{array}$ & 0.074 & 0.035 & 0.08 & Not significant \\
\hline D & $\begin{array}{c}2.3 \\
\text { (Phospholine-Pilocarpine) }\end{array}$ & 0.083 & 0.035 & 0.05 & Just significant \\
\hline E & $\begin{array}{c}2.4 \\
\text { (Phospholine-Phospholine) }\end{array}$ & 0.011 & 0.035 & 0.75 & Not significant \\
\hline F & $\begin{array}{c}3.4 \\
\text { (Pilocarpine-Phospholine) }\end{array}$ & 0.094 & 0.031 & $0.02<$ & Highly significant \\
\hline
\end{tabular}

Note. - Remainder variance $=0.073$

groups. All cases treated by Phospholine Iodide (comparison E) similarly showed no significant differences in outflow, and in these cases pressures in all but two cases became controlled.

Finally, we have to consider the remaining comparisons $\mathrm{C}$ and D. These are crossed comparisons in that pilocarpine-treated eyes, controlled (comparison C) and uncontrolled (comparison D), are compared with unrelated groups of Phospholinetreated eyes. These comparisons are only included in Table IV for completeness.

\section{Conclusions}

Our results suggest the possibility that the actions of pilocarpine and Phospholine (as already implied in the discussion) may not only differ in intensity but in nature. Although in pilocarpine-controlled cases Phospholine Iodide treatment apparently produced no significant further fall in pressure or increase in outflow, yet in pilocarpine-uncontrolled cases the subsequent use of Phospholine did produce significant lowering of pressure and increase in outflow.

In the pilocarpine series we have noted that although division into two groups (controlled and uncontrolled) can be made on the basis of intra-ocular pressure alone, yet there is no significant difference between the outflow values of the two groups. The only possible assumption which can be made about these two groups, if we believe the information provided by the tonographies, is that the pilocarpineuncontrolled group had a higher secretory rate. It is tempting to conclude from this that the ability of Phospholine Iodide to control this group might be related to an effect of the Phospholine over and above an effect on outflow. We might in fact conclude that Phospholine Iodide also had a suppressant effect on secretion.

When we consider, however, what can happen to a closed-angle glaucoma treated with Phospholine it is very difficult to accept that this drug can be credited with such a suppressant action. 
We may be justified, therefore, in assuming that the depression in intra-ocular pressure produced by Phospholine in the pilocarpine-uncontrolled eyes was not achieved by aqueous suppression; and indeed, this assumption is supported by the observations of Starr (1964) who, working with Maurice's method of estimating aqueous flow, has been unable to demonstrate any effect on secretion produced by Phospholine.

We are thus faced with the fact that in pilocarpine-controlled eyes Phospholine produces no further significant increase in aqueous outflow, yet in pilocarpineuncontrolled eyes it does; and this, in spite of the apparent fact that the difference between pilocarpine-controlled and uncontrolled eyes appears not to be a difference of outflow coefficient but of secretory rates.

Either Phospholine has two different types of effect on aqueous outflow or there is something amiss with our estimates of outflow in relation to our estimate of intra-ocular pressure. There is a possibility that we might be dealing with two different types of chronic simple glaucoma, but this is rather unlikely since in two of the cases one eye appears in the pilocarpine-controlled and the other in the uncontrolled group.

The following paradox appears to have emerged: that Phospholine Iodide is able to produce an increase of facility of aqueous outflow preferentially in eyes showing presumptive evidence of increased secretion, although without apparently having a significant effect on the secretory rate.

It seems to us that further work on this subject is called for, since the results as they stand are very difficult to explain on the basis of any facts we have at our disposal at the present time.

\section{Summary}

(1) The results of treating 18 eyes successively on pilocarpine and Phospholine Iodide are described. Pressure was significantly reduced and outflow facility significantly increased on Phospholine Iodide treatment.

(2) Pressure was successfully controlled on pilocarpine in 7 cases, and of the remaining 11 cases 9 were controlled on Phospholine Iodide. The two failed cases had tensions of 29 and $22 \mathrm{~mm}$. $\mathrm{Hg}$ respectively.

(3) In the pilocarpine-controlled cases there was no significant difference in pressure or outflow facility between Phospholine Iodide and pilocarpine.

(4) In the cases uncontrolled on pilocarpine, Phospholine Iodide significantly reduced the pressure and significantly increased the outflow facility.

(5) Ocular rigidity was not significantly changed in this series.

Note.-Since the preparation of this paper doubts have been felt about the validity of the rigidity correction for tonography. Our figures were therefore rechecked using $\mathrm{C}$ values in the uncorrected form. Table II was retested and the significance of the $C$ value column was found to be unaltered. It has therefore been assumed that the validity of our conclusions has not been altered by the use of the rigidity-corrected form of the $\mathrm{C}$ values.

\section{REFERENCES}

Becker, B., Pyle, G. C., and Drews, R. C. (1959). Amer. J. Ophthal., 47, 635.

MOSES, R., and BECKER, B. (1958). Ibid., 45, 196.

StarR, P J. (1964). Personal communication. 